\title{
Can We Estimate Felling Intervals for Barrels without Sapwood?
}

\author{
Sjoerd van Daalen | ORCID 0000-0002-0031-0186 \\ Van Daalen Dendrochronologie, H.G. Gooszenstraat 1, unit 15, 7415 CL \\ Deventer, the Netherlands \\ vandaalen@dendro.nl
}

\begin{abstract}
Oak barrels are a common find in excavations in the Netherlands. Despite the availability of numerous dendrochronological samples (staves) for each barrel, sapwood is often absent; this limits the usefulness of dendrochronology for the interpretation of the context because only the earliest possible felling date can be given. When there is no sapwood present on any staves, a close grouping of dates for the outermost rings suggests that this marks the transition from heartwood to sapwood (the heartwoodsapwood transition). If the presence of the heartwood-sapwood transition can be determined, a more accurate felling interval can be established.

Historical sources on the production of staves refer to a consistent production, whereby the sapwood and as little heartwood as possible was removed. To determine whether dendrochronological dates consistently group near the heartwood-sapwood transition, an objective and repeatable methodology was used to avoid relying on personal estimates. The dendrochronological data shows evidence for a consistent stave production process. This does not apply to all cases. In some cases, the results are unconvincing, while evidence for the absence of consistent production was also found. This is not a universally applicable method, but it can provide accurate felling intervals for a number of barrels, despite the absence of sapwood.
\end{abstract}

\section{Keywords}

oak - dendrochronology - staves - sapwood statistics - wood use 


\section{Introduction}

In the Medieval and Post-Medieval periods, oak (Quercus spp.) barrels were commonly used for the storage and transportation of a large variety of goods, both solid and liquid. Cargos found in shipwrecks especially provide insight into what was transported (for example, Hulst 1986, 73-85, Staniforth 1987, 23-24). Staves built for later assembly elsewhere were also extensively traded (Wazny 2005, 119-121).

Research on barrels show that they could be reused, possibly several times (Fawsitt 2010, 58-60) before their final use, often for some period long after production and not necessarily near the place of production (Robben 2008, $79-81)$.

In the Netherlands, barrels are regularly found in archaeological excavations, repurposed as lining for water wells (see Fig. 1).

Dendrochronological research often succeeds in dating barrel staves; many staves, often made from slow-grown oak, are available for research.

Although the absolute date for the outer tree-rings present in the staves can be supplied, the sapwood, let alone the waney edge, is often missing.

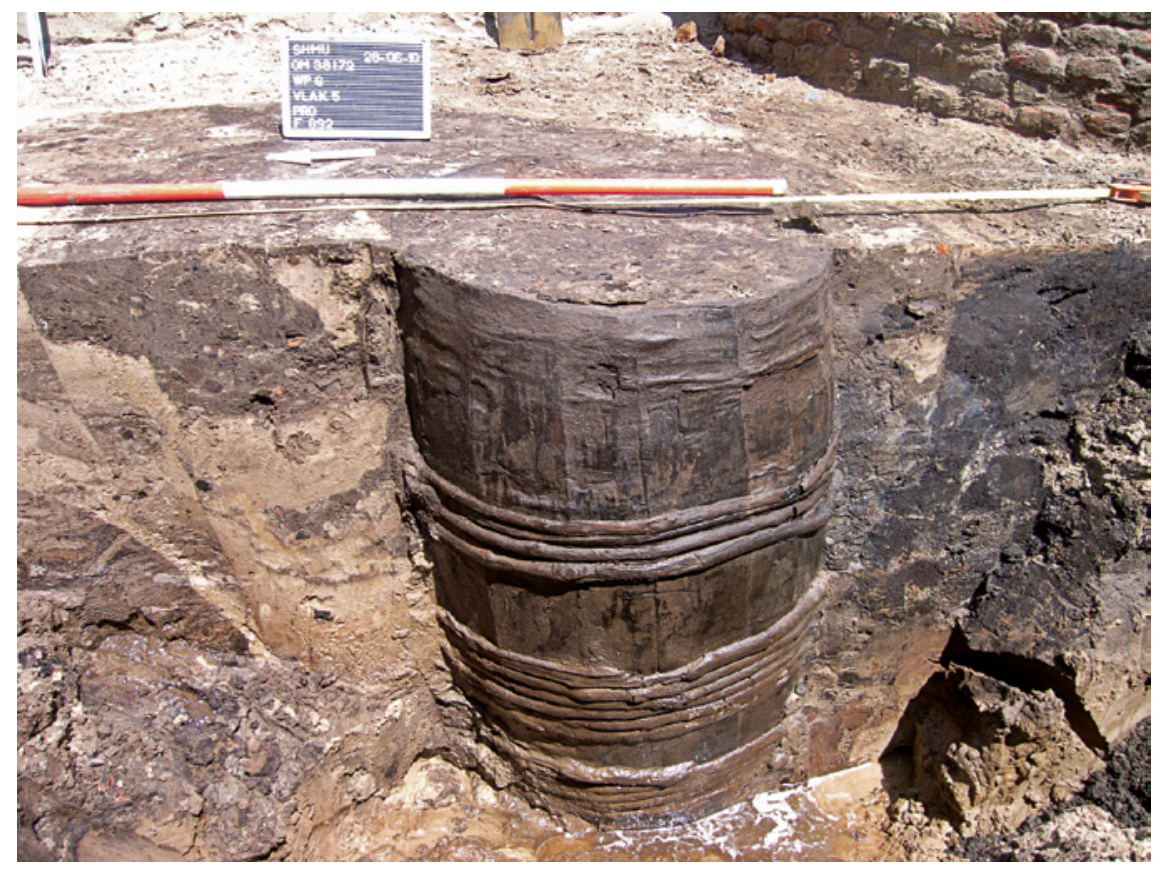

FIGURE 1 Barrel no. 3 (see Table 2) found in 's-Hertogenbosch (the Netherlands). SOURCE: BAAC BV 


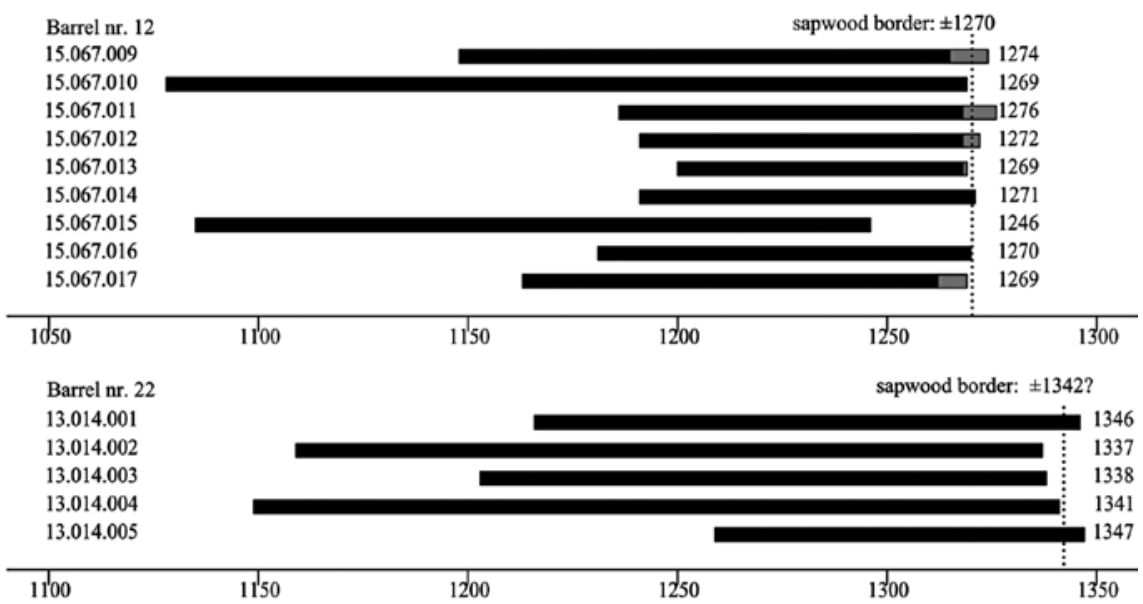

FIGURE 2 Above: dates for barrel stave grouping (mostly) around the observed heartwoodsapwood transition. Below: grouping for staves without sapwood around the presumed heartwood-sapwood transition. Heartwood is shaded black, sapwood gray.

This means only the earliest possible felling date (terminus post quem) can be established.

In some cases, however, the end dates for staves from the same barrel fall close together within a narrow interval. On occasions where sapwood is present on one or more staves, the dates for staves without sapwood group around the heartwood-sapwood transition (the transition from heartwood to sapwood, see Fig. 2).

Since wood was - and is - a limited resource, efficient use of the material can be assumed. Consistent production of the staves, whereby the less durable sapwood would be trimmed while removing as little of the durable heartwood as possible, would result in a close grouping of dendrochronological dates near the heartwood-sapwood transition. These dates can be presumed to correspond with the heartwood-sapwood transition even though no sapwood is present, so that a felling interval, instead of a terminus post quem, can be calculated.

Historical references detailing stave production are limited but point towards the consistent production of staves. Bertrand $(1777,356-359)$ describes the selection and processing of wood for cooperage: Sections of cleft oak would be trimmed of sapwood and dressed along the radial side. These semi-finished staves would be produced in large numbers (a supply for several years for a well-prepared cooper) and left to dry for two years. 


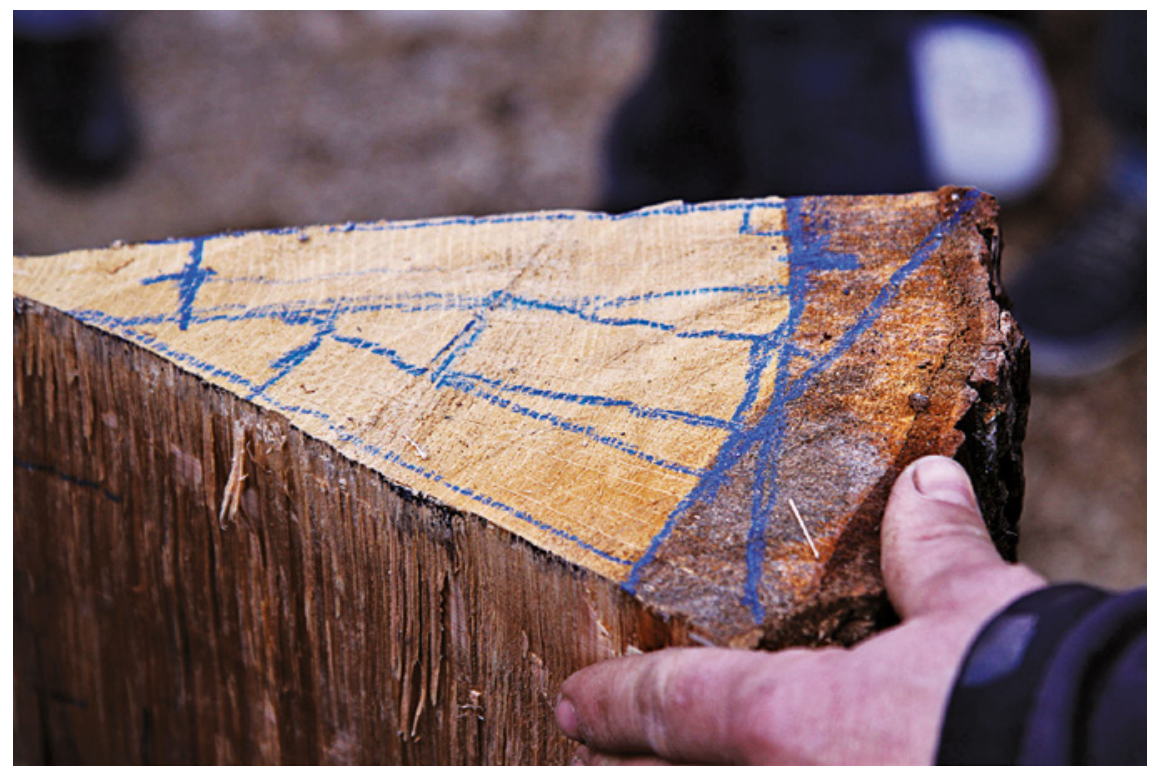

FIGURE 3 A modern-day example of staves marked out on a section of cleft oak. The staves are aligned with the heartwood-sapwood transition.

SOURCE: OLIVIER COLAS

After this period, the staves would be further shaped by tapering them at the top and bottom, and curving them to fit the circular cross-section of the barrel. Evidence for the latter is occasionally found in archaeological staves, but does not seem as commonplace as suggested by this particular source. However, this does support the notion that the sapwood has only been removed along the widest section of a stave. While modern-day coopering is focused more on storing and aging of beverages, similar notions regarding the selection and processing still apply (Bakour 2004, 27-28, Fig. 3).

The goal of this study is to determine whether it is possible to determine a felling interval for oak staves when there is no sapwood present. Although this has previously been researched (Klein et al. 2014), a further goal is to provide a uniform and repeatable method for doing so.

To test this hypothesis, dendrochronological dates for barrel staves with and without sapwood were compared. The presence of the heartwood-sapwood 
transition can only be inferred when enough staves without sapwood date within a narrow interval around the observed heartwood-sapwood transition of staves with sapwood. This is then applied to barrels where no sapwood has been observed. A minimum of five dated staves per barrel were used.

From the author's dataset, all barrels with five or more dated oak staves were selected. Only dated staves were included from each barrel. This set comprised 31 barrels and $25^{2}$ staves, dated between 1120 and 1632 (see Table 2).

The measurements were split in two groups:

(1) Control group. This contained all measurement of staves that belong to barrels where at least one stave has some sapwood: 117 staves from 13 barrels of which 44 staves (38\%) presented sapwood or the heartwoodsapwood transition. This group was used to determine the relationship between the actual heartwood-sapwood transition and date of the last ring in the other staves.

(2) Test group. This group contained the remaining 18 barrels and 135 staves. The distribution of end dates was contrasted with that of the control group.

To quantify the grouping of dates, the calendar date for the outermost heartwood ring in each stave was used. The sapwood tool from the OxCal program ${ }^{1}$ (Bronk Ramsey 2009) was used to calculate probability distributions based on Bayesian sapwood statistics, developed by Millard (2002). Felling intervals derived from these are given by the program, as well as the most likely felling year (median). When calculating felling intervals for multiple dates, the program determines if overlapping felling intervals coincide. This is indicated for each measurement with the agreement index (AI) "A". The dates with high AIs form a combined interval.

Staves for which the heartwood-sapwood transitions are sufficiently closegrouped have a high agreement index. This allows for a common felling interval to be calculated, one which is more accurate than the felling intervals for individual measurements. Any present sapwood rings further increase the accuracy.

Measurements with a heartwood-sapwood transition that falls outside of the common interval have a low agreement index. This is indicated by a warning.

For this study, all staves without sapwood were treated as if the outermost ring corresponds with the heartwood-sapwood transition (i.e., zero sapwood rings). A low agreement index for a stave shows that the outermost ring cannot

1 Available online at https://c14.arch.ox.ac.uk/oxcal/OxCal.html. 
be considered as a heartwood-sapwood transition. A high AI means that the outermost ring is probably the heartwood-sapwood transition.

The program was used without adjustments to ensure that the results were uniform and could be duplicated or applied to other data.

To calculate felling intervals, a "sapwoodmodel", describing the distribution of the number of sapwood rings, has to be defined. Although additional parameters, such as the average growth $\left(b_{\mathrm{m}}\right)$ and cambial age of the tree $\left(b_{\mathrm{r}}\right)$, can be included in the sapwoodmodel, only the number of sapwood rings $(a)$ and the variation $(\delta)$ has been taken into account. Because the number of sapwood rings differs between parts of Europe (Haneca et al 2009, 3-5), a simple division based on the provenance of the wood was made as follows:

Wood from areas adjoining the Netherlands, as well as the French Loire valley, was assigned a Northwest-European provenance, while wood from Poland, the Baltic States, and (possibly) Belorussia was assigned a Baltic origin. A different sapwoodmodel was used for each provenance group. The OxCal parameters are shown in Table 1.

Whereas the staves in each barrel were used to determine systematic production, the actual felling interval was based on the number of trees. Assuming each stave represents a single tree means that data for the same tree would have been used several times in the same calculation. Since additional overlapping intervals further reduce the range for the felling interval, this would have resulted in false accuracy in the range for the felling interval. One specific case is barrel no. 21, where the data for five staves showed consistent production, but since all staves were determined to be made from the same tree, the felling interval was based on that one tree.

Staves from the same tree were identified using the criteria proposed by Beuting (2011, 274).

TABLE 1 OxCal parameters for the sapwoodmodels

Provenance

\begin{tabular}{lllll} 
& $\boldsymbol{a}$ & $\boldsymbol{b}_{\mathrm{r}}$ & $\boldsymbol{b}_{\mathrm{m}}$ & $\delta$ \\
\hline NW-EU & 2.739918 & 0 & 0 & 0.374077 \\
Baltic & 2.752901 & 0 & 0 & 0.293951 \\
\hline
\end{tabular}

The Northwest-European (NW-EU) model is based on the author's data, and the Baltic model is based on sapwood data by Wazny (1990). 
The $t$ value after the Hollstein-transformation $\left(t_{\mathrm{HO}}\right.$; Hollstein 1980, 14) and Gleichläufigkeit score were calculated using PAST $4 .{ }^{2}$

A secondary OxCal run was then performed for each barrel with consistent stave production, but instead of the data for each stave, only the data for each tree was used.

\section{$3 \quad$ Results}

\subsection{Control Group (Sapwood Present)}

There was no barrel in the control group where the AI was high for all staves.

In the best cases a large proportion of the staves showed a high AI. Staves with a low AI dated too early by a few years. This is illustrated by barrel no. 3 (see Fig. 4), where out of 18 analyzed staves, 14 staves (five with and nine without sapwood) belong to the same combined interval.

For barrels where half or fewer of the staves form a combined interval, it becomes increasingly probable that the combined interval was the result of chance rather than the systematic production of the wood, especially since this coincides with a decrease in the sample depth per barrel.

The data for the control group provides two possible explanations for the measurements with a low agreement index. The first explanation is that the outer ring of these staves does not correspond with the heartwood-sapwood transition and that some (additional) heartwood has been removed. This is shown by staves that belong to a single tree. In the control group, there were five occurrences of staves originating from the same tree, and in two such cases, a stave with a low AI was made from the same tree as a stave with a high AI.

The other explanation is that the outer ring does correspond with the heartwood-sapwood transition, but the stave was used some years after production. Nine staves in the control group $(20 \%)$ presented sapwood or the heartwood-sapwood transition but dated too early to be included in the combined interval determined by other staves with or without sapwood from the same barrel, such as barrel no. 5 (see Fig. 5 for 1GCoo 46 A).

In these cases, stockpiling or reuse seems likely, with stockpiling being more plausible, since in all but one case the staves shared the same provenance and dated too early by a decade at most.

One exception was barrel 8 , where a stave with sapwood predated the remaining stave by more than a century (see Fig. 6). It seems unlikely that the stave actually belongs to this barrel.

2 Distributed by Sciem, Vienna (Austria), www.sciem.com. 
AI Barrel nr. 3

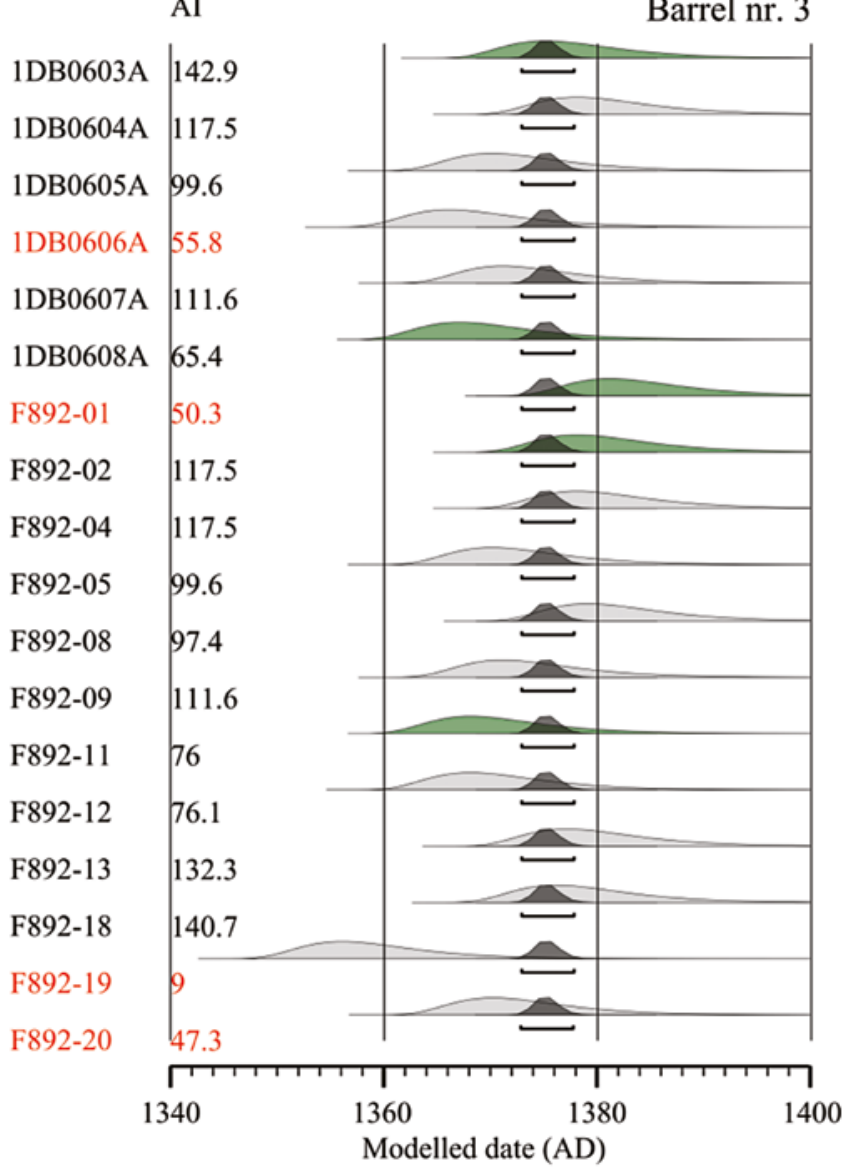

FIGURE 4 OxCal generated probability distribution curves for the staves of barrel no. 3. Each line represents one stave. Probability distribution curves are shaded light gray (without sapwood) or green (with sapwood). The combined interval is shaded dark gray and the bracket below shows the $2 \delta$ range (the estimated felling interval). For staves that are not part of the combined interval (i.e., a low AI), the keycode and AI are marked in red.

As the percentage of staves with a high AI decreased, the combined interval could be increasingly attributed to chance instead of the systematic processing of the wood. When less than three staves and/or half or fewer staves formed a combined interval, the outcome was discarded, especially since this coincided with a decrease in the sample depth per barrel (see Table 2). 
AI

Barrel nr. 5

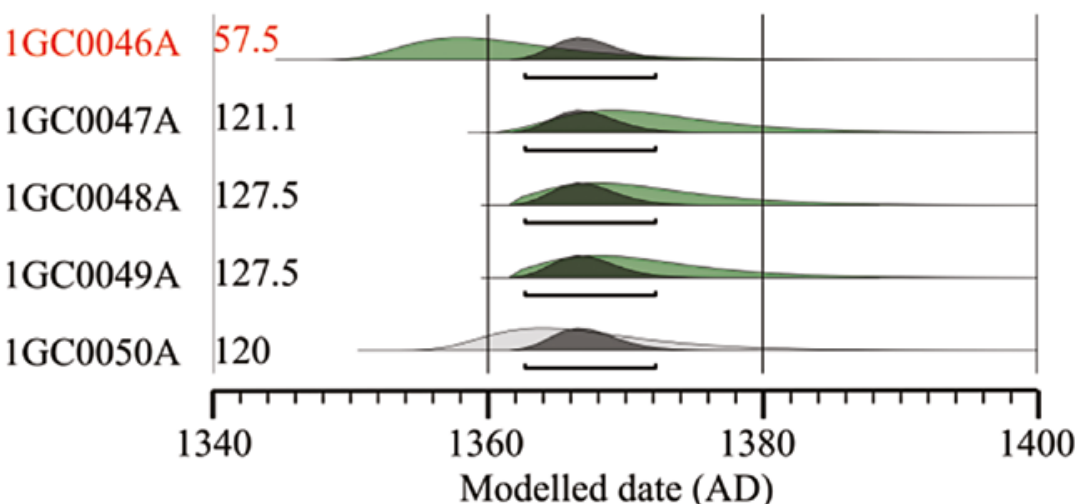

FIGURE 5 OxCal generated probability distribution curves for the staves of barrel no. 5 . Each line represents one stave. Probability distribution curves are shaded light gray (without sapwood) or green (with sapwood). The combined interval is shaded dark gray and the bracket below shows the $2 \delta$ range (the estimated felling interval). For staves that are not part of the combined interval (i.e., a low AI), the keycode and AI are marked in red.

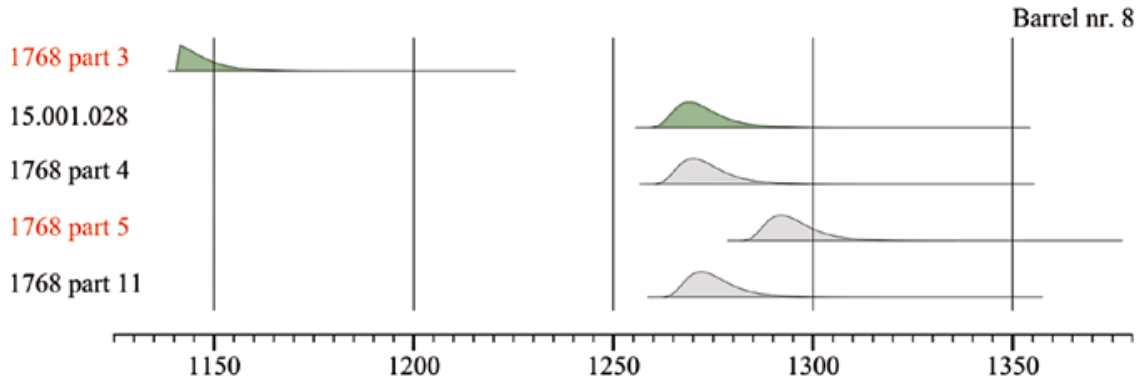

FIGURE 6 OxCal generated probability distribution curves for the staves of barrel no. 8 .

Each line represents one stave. Probability distribution curves are shaded light gray (without sapwood) or green (with sapwood). The combined interval cannot be calculated with 1768 part 3 present in the collection. For staves that are not part of the (final) combined interval (i.e., a low AI), the keycode and AI are marked in red.

\subsection{Test Group (No Sapwood Present)}

In the test group, two barrels were found where all staves (five in both cases) formed a combined interval.

The results for the remaining barrels were, in part, similar to those for the control group. The best example was given by barrel no. 30 (see Fig. 7), where 
AI

Barrel nr. 30

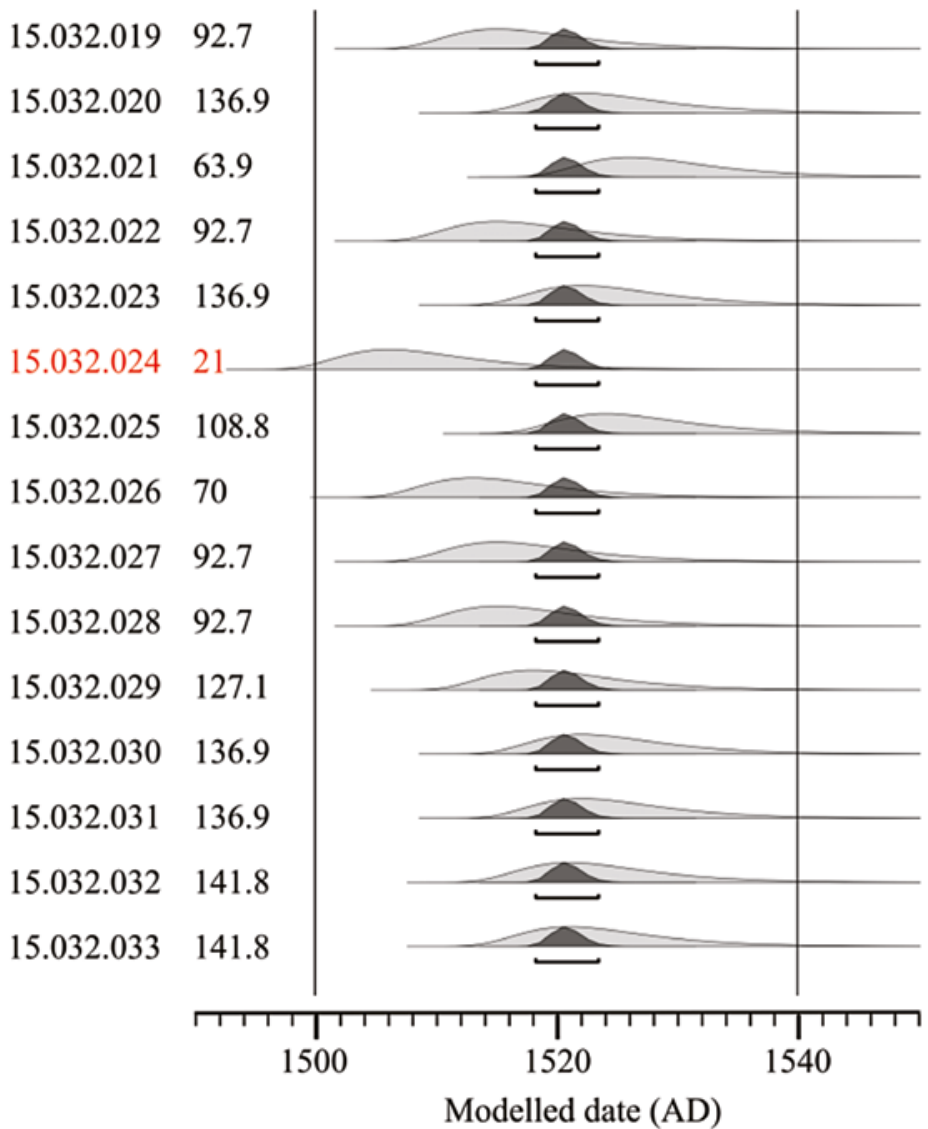

FIGURE 7 OxCal generated probability distribution curves for the staves of barrel no. 3o. Each line represents one stave. Probability distribution curves are shaded light gray (without sapwood). The combined interval is shaded dark gray and the bracket below shows the $2 \delta$ range (the estimated felling interval). For staves that are not part of the combined interval (i.e., a low AI), the keycode and AI are marked in red.

the end dates for 14 out of 15 staves fell within such a narrow range that, for practical purposes, it could be assumed to be the heartwood-sapwood transition.

The notable difference with the control group is that there were (almost) fully analyzed barrels where only a small percentage of the staves formed a combined interval, such as barrel no. 15 (see Fig. 8). This means that more heartwood was removed during the processing of the wood for these barrels compared to those in the control group. Table 2 gives a summary of the data. 


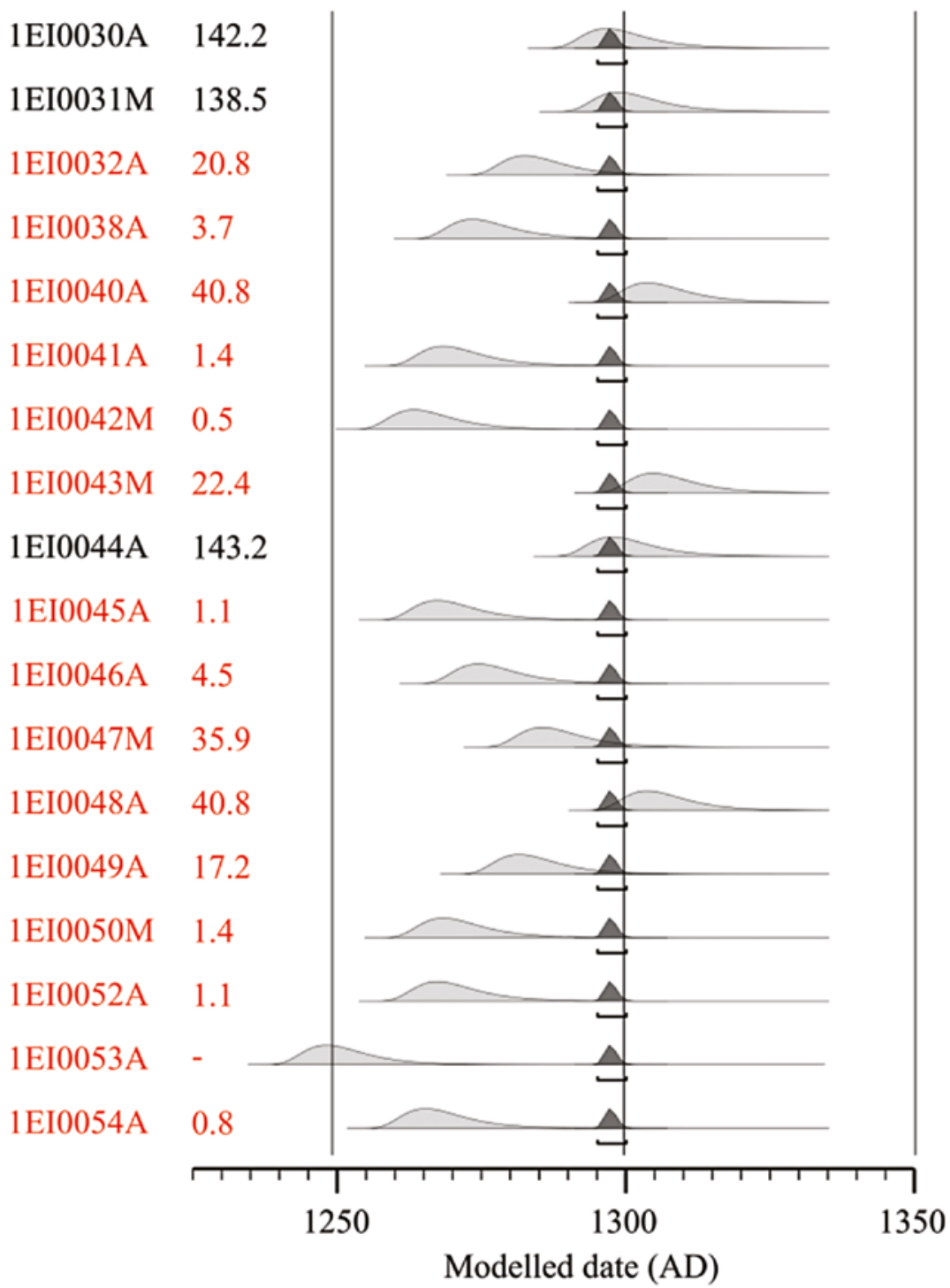

FIGURE 8 OxCal generated probability distribution curves for the staves of barrel no. 15. Each line represents one stave. Probability distribution curves are shaded light gray (without sapwood). The combined interval is shaded dark gray and the bracket below shows the $2 \delta$ range (the estimated felling interval). For staves that are not part of the combined interval (i.e., a low AI) the keycode and AI is marked in red. 
TABLE 2 Summary of the data

\begin{tabular}{|c|c|c|c|c|c|c|c|c|c|}
\hline $\begin{array}{l}\text { Barrel } \\
\text { no. }\end{array}$ & Group & $n$ & $\begin{array}{l}n \text { sw } \\
\text { (avg.) }\end{array}$ & $n$ CI (\%) & HST & $\Delta \mathbf{H W}$ & Trees & $\begin{array}{l}\text { OxCal median } \\
\text { ( } 2 \delta \text { range })\end{array}$ & $\begin{array}{l}\text { Provenance } \\
\text { group }\end{array}$ \\
\hline 1 & Control & 5 & $2(5 \cdot 5)$ & $2(40.0)$ & $1272^{1}$ & 20 & 2 & $1286(1279-1295)$ & NW-EU \\
\hline 2 & Control & 6 & $5(10.8)$ & $5(83 \cdot 3)$ & $1490^{1}$ & 91 & 5 & $1495\left(1493^{-1500}\right)$ & Baltic \\
\hline 3 & Control & 18 & $5(3.4)$ & $14(77.8)$ & $1359^{2}$ & 12 & 11 & $1374(1371-1377)$ & NW-EU \\
\hline 4 & Control & 11 & $7(8.9)$ & $9(81.8)$ & $135^{2}$ & 7 & 9 & $1374\left(1373^{-1376)}\right.$ & Baltic \\
\hline 5 & Control & 5 & $4(6.3)$ & $4(80.0)$ & $135^{\circ}{ }^{2}$ & $\mathrm{~N} / \mathrm{A}$ & 4 & $1368(1363-1373)$ & Baltic \\
\hline 6 & Control & 11 & $1(3.0)$ & $8(72.7)$ & $1306^{2}$ & 20 & 8 & $1322(1318-1326)$ & NW-EU \\
\hline 7 & Control & 6 & $1(0.0)$ & $3(50.0)$ & $133^{2}$ & 15 & 3 & $135^{2}(1346-1359)$ & NW-EU \\
\hline 8 & Control & 5 & $2(8.5)$ & $3(6 \circ .0)$ & $125^{6}$ & -22 & 3 & $1271\left(1265^{-1278}\right)$ & NW-EU \\
\hline 9 & Control & 8 & $6(9.5)$ & $4(50.0)$ & $1445^{2}$ & 11 & 4 & $1453\left(145^{0}-1459\right)$ & Baltic \\
\hline 10 & Control & 19 & $1(3.0)$ & $13(68.4)$ & $1286^{2}$ & 29 & 13 & $1301(1298-1304)$ & NW-EU \\
\hline 11 & Control & 8 & $1(2.0)$ & $7(87 \cdot 5)$ & $15^{6} 7^{2}$ & 9 & 7 & $1582(1579-1586)$ & Baltic \\
\hline 12 & Control & 10 & $6(6.0)$ & $9(9 \circ .0)$ & $1270^{2}$ & 24 & 9 & $1282(1279-1285)$ & NW-EU \\
\hline 13 & Control & 5 & $3(14.0)$ & $3(6 \circ .0)$ & $1442^{2}$ & -11 & 3 & $1460\left(145^{8-1466)}\right.$ & Baltic \\
\hline 14 & Test & 8 & - & $3(37 \cdot 5)$ & & & 3 & & NW-EU \\
\hline 15 & Test & 18 & - & $3(16.7)$ & & & 3 & & NW-EU \\
\hline 16 & Test & 10 & - & $7(70.0)$ & $1492^{3}$ & 15 & 7 & $1506(1502-1510)$ & NW-EU \\
\hline 17 & Test & 5 & - & $3(60.0)$ & $132^{3}$ & 12 & 3 & $1348(1342-1355)$ & NW-EU \\
\hline 18 & Test & 5 & - & $2(40.0)$ & & & 1 & & NW-EU \\
\hline 19 & Test & 5 & - & $3(6 \circ .0)$ & $1287^{3}$ & 15 & 3 & $1302(1296-1309)$ & NW-EU \\
\hline 20 & Test & 6 & - & $1(16.7)$ & & & & & NW-EU \\
\hline 21 & Test & 5 & - & $5(100.0)$ & $1624^{3}$ & - & 1 & $1644(1634-1658)$ & NW-EU \\
\hline 22 & Test & 5 & - & $5(100.0)$ & $1342^{3}$ & - & 5 & $1357\left(1353^{-1363)}\right.$ & Baltic \\
\hline 23 & Test & 5 & - & 3 (6o.o) & $1342^{3}$ & 33 & 3 & $135^{8}\left(135^{2-1} 365\right)$ & Baltic \\
\hline 24 & Test & 6 & - & $3(50.0)$ & & & 3 & & NW-EU \\
\hline 25 & Test & 9 & - & $8(88.9)$ & $1331^{3}$ & 56 & 8 & $1346\left(1343^{-135^{\circ}}\right)$ & NW-EU \\
\hline 26 & Test & 8 & - & $6(62.5)$ & $1424^{3}$ & 12 & 5 & $1440(1436-1445)$ & NW-EU \\
\hline 27 & Test & 5 & - & $\mathrm{o}(0.0)$ & & & o & & NW-EU \\
\hline 28 & Test & 6 & - & $3\left(5^{\circ .0}\right)$ & & & 3 & & NW-EU \\
\hline 29 & Test & 8 & - & $4(50.0)$ & & & 3 & & NW-EU \\
\hline 30 & Test & 15 & - & $14(93 \cdot 3)$ & $15^{\circ} 5^{3}$ & 13 & 14 & $15^{21}\left(15^{18-1524)}\right.$ & NW-EU \\
\hline 31 & Test & 6 & - & $5(83 \cdot 3)$ & $1576^{3}$ & 41 & 5 & $1591(1587-1596)$ & Baltic \\
\hline
\end{tabular}

$N$, number of staves; $n$ sw (avg), number of staves with sapwood and the average number of sapwood rings; $n \mathrm{CI}(\%)$, the number and percentage of staves in the combined interval; HST, the calendar year for the heartwood-sapwood transition, based on the combined interval of (1) observed sapwood exclusively, (2) both observed sapwood and estimated heartwood-sapwood transition, and (3) estimated heartwoodsapwood transition exclusively; $\Delta \mathrm{HW}$, average number of missing heartwood rings for staves not included in the combined interval (negative numbers indicate stockpiling or reuse); Trees, the numbers of trees used to calculate the felling interval. 
The large spread of dates of last measured rings, combined with the high sample depth per barrel, indicates that this is not coincidence, but the result of more processed wood. In addition, staves from the same tree provide evidence for the processing in the same way as those from the control group and with the same results, i.e., in five cases, staves were made from the same tree, with two cases of staves with low and high AIs originating from the same tree. Although some staves form a combined interval, it is not possible to estimate the amount of removed heartwood. The lack of consistent production means that there is no reliable date for the heartwood-sapwood transition.

It is likely that the effect of stockpiling plays an important role in the spread of end dates, but it is unlikely to be the sole cause for the spread of end dates over several decades.

\section{Discussion}

\subsection{Coopering and Purpose}

Barrels were made for different purposes. A distinction is made between wet cooperage (for liquids), dry cooperage (for dry goods), and white cooperage (tubs and buckets for mostly liquids) (Staniforth 1987, 21). Only the first two are relevant in this case. The demands set for the barrel could affect the production of the staves. A watertight fit requires higher standards of production which results in heavier processing of the wood. This is most evident in the test group, where the staves are more processed, and a distinct lack of consistent production can be found.

With the lower standards for dry coopering, sapwood remains could be overlooked without much concern. In addition, the outer rings would be closer to the heartwood-sapwood transition. Especially in the Baltic barrels, the occurrence of sapwood, the number of staves with sapwood and the amount of sapwood are higher than those in the Northwest-European group (see Table 2). This could reflect the fact that mostly solid goods were traded in these barrels.

\subsection{Sample Size}

The number of staves analyzed per barrel affects the outcome for the combined interval. In the case of barrel no. 3 the initial six staves could be fitted into a combined interval. After analyzing 12 additional staves, a low AI occurred, including in one of the staves initially researched. This was caused by the combined interval shifting two years towards the present. The initial felling interval fell around 1372 ( $2 \delta$ range $1368-1377)$, whereas after additional research, the felling interval was situated around 1374 ( $2 \delta$ range $1371-1377)$. This 
had the results that a stave with an earlier date (1DBo6o6A, see Fig. 4) was no longer part of the combined interval as a result of the analysis of additional staves. A sampling bias (i.e., a preference for wider, less processed, staves or staves with sapwood) could also contribute to a higher spread of dates for outer heartwood ring when additional samples are researched.

\subsection{Estimation Errors}

Any felling interval that can be calculated is likely to be an underestimation for several reasons. Because of the natural variation of sapwood, the removal of a few rings of heartwood could still result in a high AI, especially if this applies to several staves; this lowers the median of the combined interval. The average growth of the wood also affects the combined interval. According to Tyers $(2008,94)$, narrower rings result in an underestimation of the felling interval.

When applied to the interpretation of the archaeological context of a barrel, reuse and stockpiling puts additional years between the felling and the final use of the wood.

\section{Conclusion}

The results show that the consistent production of staves did occur, but not exclusively. In some cases, it was not clear whether staves were produced consistently or not, whereas other cases clearly showed that staves were not produced consistently. Staves from barrels where sapwood is present were more likely to be consistently produced. The processing of the staves was often related to the goods for which the barrels were intended; this influenced the dendrochronological results.

A large number of staves had to be researched to be able to determine the manner of production. However, the production did not always result in an acceptable grouping of end dates, and a felling interval could only be calculated in some cases. This limits the successful application of the method to 12 out of 31 barrels (39\%). Since this can only be considered a pilot study, other researchers are encouraged to apply this method to their respective datasets so that the effect of time period and provenance can also be considered.

\section{References}

Bakour R. 2004. Influence de l'espèce et de la provenance des deux principaux chênes français (Quercus robur L.; Quercus petraea Liebl.) sur la structure anatomique et 
les propriétés physiques du bois de merrain. Thesis, Ecole Nationale du Génie Rural, des Eaux et des Forêts (ENGREF), Nancy.

Betrand J.E. 1777. Art du Tonnelier. In Description des Arts et Métiers. Tome VII.

Beuting M. 2011: Dendro-organology? The dendrochronological method applied to musical instruments. In: P. Fraiture (ed.), Tree Rings, Art, Archaeology, Proceedings of an international Conference, Brussel: Royal Institute for Cultural Heritage: 273-283.

Bronk Ramsey C. 2009. Bayesian analysis of radiocarbon dates. Radiocarbon 51(1): 337-36o.

Fawsitt S. 2010. Casks \& 16th Century Trade in Northern Europe: A Study of the Cargo from the Drogheda Boat. University of Southern Denmark, Odense.

Haneca K., Čufar K., Beeckman H. 20o9. Oaks, tree-rings and wooden cultural heritage: a review of the main characteristics and applications of oak dendrochronology in Europe. Journal of Archaeological Science 36: 1-11.

Hollstein E. 1980. Mitteleuropäische Eichenchronologie. Philipp von Zabern, Mainz am Rhein.

Hulst R. 1987. Casks as a packing material: an archaeological typology and a historical reconstruction. In J. Gawronski (ed.), Amsterdam Project: Jaarrapport van de Stichting VOC-Schip "Amsterdam" 1986: 73-85. Stichting voc-Schip "Amsterdam", Amsterdam.

Klein A., Nemestothy S., Kadnar J., Grabner M. 2014. Dating furniture and coopered vessels without waney edge - Reconstructing historical wood-working in Austria with the help of dendrochronology. Dendrochronologia 32(1): 90-96.

Millard A. 2002. A Bayesian approach to sapwood estimates and felling dates in dendrochronology. Archaeometry 44: 137-143.

Robben F. 2008. Spätmittelalterliche Fässer als Transportverpackung im hansischen Handelssystem. Archäologische Informationen 31(1-2): 77-86.

Staniforth M. 1987. The Casks from the Wreck of the William Salthouse. Australian Historical Archaeology 5: 21-28.

Tyers C. 2008. Bayesian interpretation of tree-ring dates in practice. Vernacular Architecture. 39: 91-106.

Wazny T. 1990: Aufbau und Anwendung der Dendrochronologie für Eichenholz in Polen. Ph.D. dissertation, Universität Hamburg, Hamburg.

WaznyT. 2002. The origin, assortments and transport of Baltic timber. In: C. Van deVelde, H. Beeckman, J. Van Acker, F. Verhaeghe (eds), Constructing Wooden Images: proceedings of the symposium on the organization of labour and working practices of late Gothic carved altarpieces in the Low Countries: 115-126. vU B Brussels, Brussels. 